\title{
Reflection and Construction of Higher Vocational Curriculum Based on Professional Quality Education
}

\author{
Wei Chiwen, ${ }^{1, \text { a }}$ and Wei Qin ${ }^{2, b}$ \\ ${ }^{1}$ Xiangyang Vocational and Technical College, Xiangyang, Hubei 441050, China \\ ${ }^{2}$ corresponding author: Emergency Department, Xiangyang Central Hospital, Affiliated Hospital \\ of Hubei University of Arts and Sciences, Xiangyang, Hubei 441050, China \\ a407732018@qq.com ${ }^{\text {b } 1444672356 @ q q . c o m ~}$
}

Keywords: professional quality education; higher vocational courses; construction

\begin{abstract}
The training objective of higher vocational education is cultivating superior skille $\mathrm{d}$ talents. And improving the professional quality of students is its important connotation. A $\mathrm{s}$ a pattern of educational activities, curriculum is the foundation and the key of talent train ing. Therefore, it is necessary to examine the curriculum construction of higher vocational e ducation from the perspective of vocational literacy education. From the perspective of prof essional literacy, it is necessary to reflect and reconstruct the curriculum of higher vocation al education. In order to solve the basic problem of students' professional literacy deficiency in higher vocational curriculum.
\end{abstract}

\section{Introduction}

With the rapid development of higher vocational education, the attention on its quality te nds to focus on students' professional literacy. As a pattern of educational activities, curricu lum is the carrier to realize educational objectives and the vital link of educational thoughts transforming into educational outcomes, and the core of cultivating talents. Therefore, base $\mathrm{d}$ on the improvement of talent cultivation quality, it is a necessity to inspect higher vocati onal curriculum through professional quality. From the perspective of professional quality, $t$ he fundamental problem of higher vocational curriculum is the deficiency of education on st udents' professional quality, and it is necessary to reconstruct the curriculum.

\section{Organization of the Text}

\section{The basic theory of professional quality}

As to the connotation of professional quality, different interpretation is presented from dif ferent understanding. In academic field, the connotation of professional quality has been gen erally considered that it includes professional competence, professional consciousness, profess ional attitude and professional ethics. While, the profession holds more specific understandin $\mathrm{g}$ of professional quality, including professional values, cooperation, the awareness of servic e and obedience, innovation and entrepreneurship, ethics and professional skills, etc. The hig her vocational education is aimed at cultivating superior skilled talents, which includes two aspects "superior quality" and "superior skill". Professional quality is the norm and requirem ent for a person to be engaged in the occupation, which mainly includes professional skill accomplishment, professional consciousness, professional ethics and professional attitude. The refore, the professional quality of higher vocational students can be divided into explicit pro fessional quality and recessive professional quality. Explicit professional quality mainly refer $\mathrm{s}$ to basic professional knowledge and professional skills, including basic theoretical knowle dge, practical ability and technical innovation ability, etc. And recessive professional quality includes political quality, moral quality, cooperative quality, and good psychological quality, etc. If using the famous iceberg theory to explain what is professional quality, it can be c 
onducted by assuming a person's accomplishment as an iceberg, and the visible part of an i ceberg is knowledge, skills and behavior, which would be the explicit accomplishment; whil e the hidden part would be the recessive accomplishment, which includes self-image, person ality quality, professional attitude, professional consciousness and professional ethics. The tot al professional quality that a person possesses is the sum of the explicit and recessive quali ties. Explicit quality is only a small part of professional quality. The most part of professio nal quality belongs to recessive quality. For example, " Germans are not only concerned wi th the operational skills, but also many other aspects that would affect the formation of ope rational skills in comprehensive, detailed and in-depth analysis. Because of the specific oper ational skills, at least, are the organic combination of knowledge, psychological operation $\mathrm{pr}$ ocess and practice, and involve the cultivation of the professional attitude and good behavio $r$ habits, the enhancement of psychological quality, intelligence and the aesthetic consciousne ss, etc." [1]Therefore, the recessive quality is vital for the future career development of a $p$ erson.

\section{The fundamental problem of vocational course -- the lack of professional literacy ed ucation}

The construction of the world vocational education curriculum has shown the developing ten dency of knowledge-oriented, competence-based and vocational diathesis education. Vocational education has gradually become the hot spot of the curriculum construction and reform, reflec ting the society's deepening understanding of vocational education. On the basis of students' $d$ ominant professional quality, the higher vocational education must improve students' recessive professional quality according to the needs of social development. And achieve the objective o $\mathrm{f}$ cultivating talents of high skilled abilities. However, the current higher vocational education i $\mathrm{n}$ our country has the tendency which deviates from the development trend, reflecting on the $\mathrm{c}$ ourse design and construction, and presented by:

\section{Curriculum objectives: the decline of students' subjective goals}

The object of education is a person, although the vocational education had the characteristic $\mathrm{s}$ of pertinence, specialized jobs, but to promote people's all-round sustainable development is all education including vocational education. Course objectives, therefore, must be the dialectic al unification of individual subject and social subject, both should be fully reflected in the curr iculum goal. However, the design and implementation of the current higher vocational curricul um show the characteristics of declined individual subject and strong social subject. The curric ulum goal, curriculum setting and curriculum standards all focus on the demand of the social $s$ ubject of position pertinence, and ignore the individual interest characteristics and inner needs. Meanwhile, the objective of the individual subject concerned in the curriculum construction of higher vocational education is to measure the low level of employment. That is, it is generall $y$ satisfied with the general needs of living and living. It is narrowly understood as "work" by "occupation". It is considered that the completion of a job by a professional person is all its meaning and neglects the spiritual needs of human beings. Dewey thought "profession is a con crete noun, it includes both professional and transactional profession, including any kind of arti stic ability, special ability of scientific and effective development of citizen morality”. [2]Thus the connotation of professional should be very rich. It not only has specific work tasks, but als o includes the overall development of people.

\section{Curriculum: the utilitarian tendency is serious}

In the "employment oriented" wave of utilitarianism, the vocational education is understood as tools of solving the specific tasks, and it becomes vocational training. Since the specializati on of higher vocational education, schools, students, parents failed to understand the essential c haracteristics of vocational education. The "ability standard", and "professional supremacy" are generally shown to be utilitarian. And it causes that students aren't interested in professional s kills outside of knowledge and accomplishment, especially the contents which are not directly related to "practical" and "skills". And finally it makes the vocational literacy education badly missed. In order to meet the needs of professional, the utilitarian courses division is becoming 
more and more sophisticated, based on the working process, the modular teaching, task driven, etc. On the basis of specialization and skills, the result is that the fusions among courses are difficult. The teaching is full of tool rationality, while students lack of value rationality, such a s freedom spirit, innovation consciousness, critical thinking ability and so on.

\section{The curriculum implementation: knowledge-based orientation is obvious}

The main objectives and tasks in the process of higher vocational curriculum implementatio $\mathrm{n}$ focused on imparting knowledge and skills training. Besides, the assessment and evaluation $\mathrm{f}$ ocus on knowledge, and skills, etc. And they are judged by the number of knowledge and skill s. Even the evaluation of the students' professionalism also simply follows the methods. Mast ering how much knowledge is used as an evaluation standard of professional quality high and low. The excessive reliance on knowledge, and excessive pursuit of skills make the knowledg e cover all the roles and significance which education has. The vocational literacy education $g$ oes to the wrong path of formulation, simplicity and theoretical astray. The vocational literacy education with rich, complex and practical characteristics has been dissimilated. Though studen ts may possess a lot of professional knowledge, a perfect moral personality can not be formed because of the lack of thought, no emotion, lack of personality and spiritual desolation. At last, the "man" is instrumented in education.

\section{Construction of higher vocational education based on professional literacy education}

With the rapid changes of technology, the connotation of the professional ability is in great changes. Professional quality embodies characteristics of ontology in the field of professional c areer. Meanwhile, it reflects the fulfillment of the spiritual life of the professional man. The pr ofessional ability is only a kind of education, and rich professional training of talents is the ba sic goal of our pursuit, this is the basic idea of curriculum construction.

The goal of the course focuses on the concept of coordinated development between ma $n$ and profession.

Any education involves the fundamental problems of "what kind of people to cultivate", "h uman sustainable development" and so on. The key to cultivating high skilled talents in higher vocational education is not only having good professional quality, but also having a solid skill level. Therefore, the talents trained in higher vocational education are not a single professiona l accomplishment or skill training, but the unity of professional quality and professional skills. So the curriculum should mainly highlight the concept of human development in the goal orie ntation, people oriented, and promote people to achieve self-development, spiritual enrichment, personality perfect. Vocational education must be unified with the "comprehensive and sustaina ble development of human beings". The comprehensive and sustainable development of human beings is also integrated with the realization of the overall development of the career. Pursue the "overall development" in the "career". Therefo

\section{The content of the curriculum emphasizes the integration of professional quality and professional post.}

After the reestablishment of the curriculum objectives, a key task is to integrate and reconst ruct the content of the curriculum so as to integrate knowledge, skills and literacy education. At present, the disengagement of vocational education curriculum and professional requirement $s$ leads to the difficulties in the training of professional literacy. In fact, professional activities are an organic whole, including knowledge, skills, beliefs, attitudes, behaviors, etc., which have their own logical connections and cultural characteristics. Higher vocational education should build a professional quality education system according to the growth law of higher vocational students and the development needs of the professional and social people in the society. On o ne hand, higher vocational education should design the curriculum content of professional liter acy education according to the facts of students. By the reform of curriculum objectives, educa tional contents, teaching methods and assessment methods, we build a professional quality edu cation system, so that we can get a clearer expression of the professional quality of education tasks in teaching content. On the other hand, we should design the first class and the second c 
lass, the school education and the social practice, the students' self-cultivation and other educat ional platforms and carriers systematically. And make the interaction between the subjective an $\mathrm{d}$ the objective, and form the resultant force. In addition, we have to strengthen professional lit eracy education throughout the process, and let students gain the moral and emotional experien ce of the professional in various learning practices, and improve the level of professional litera cy consciously.

At present, "carrying out education through curriculum and encouraging students to learn in a variety of activities and practice are the two most important ways of moral education in foreign universities." [3]American universities lay emphasis on shaping the students' vie ws of occupation and values in the professional education. They have to answer the followi ng questions in the study of professional courses: "what kind of history and tradition does $t$ his major possess? What is its relations with social and economic problems? what kind of ethical and moral issues does it reflect?" [4]These questions provide a good reference for th e professional quality education in China. Integrating professional quality education in differ ent courses and combining instrumental reason with value rationality can improve the efficie ncy of education.

Integration of the curriculum standards with the occupation standards

The integration of the occupation standards and curriculum standards requires educators a nd industries and enterprises to design the professional talent training standards on the basis of professional teaching needs. Through the analysis of occupation standards and typical $\mathrm{w}$ ork projects and tasks, educators develop occupation standards into curriculum standards in 1 ine with higher vocational personnel training requirements, providing the overall content fra mework and guiding outline for higher vocational personnel training. After the formation of the curriculum standards, how to carry out the instructional design of curriculum and curri culum system is also an important part in higher vocational talents training.

The implementation of curriculum standards demands well-ordered post (Group)-oriented c urriculum types, curriculum structure and curriculum modules, highlighting the importance of curriculum standards and content construction. Higher vocational education focuses on the education of students' occupational production, skills and management to improve their voc ational and technical level. It designs teaching plans based on the needs of occupational po st group, determines the training targets and talent cultivation specifications, and defines occ upational ethics knowledge and abilities higher vocational graduates should have. Therefore, teachers should master the occupational education knowledge, norms and goals, and explore the match point of implementation of professional quality education in the disciplines.

\section{Implementation of curriculum based on occupational context}

Context-based design is the creation of a specific task through some platform and carrier, using post simulation, plot correlation and real atmosphere to involve the students. "Only i $\mathrm{n}$ the specific workplace can occupational quality be demonstrated. Adaptation ability should depend on contact information change rather than the study of systematic theoretical kno wledge divorced from work tasks." [5]The implementation of context-based curriculum requi res the occupation practice to be incorporated into the teaching content and establish real jo b-related tasks and occupation standards. Through the use of real occupational norms, learni ng in the real context-based workplace can be implemented. For example, the establishment of cooperation with enterprises in order to make the study associated with future workplac e practices, the construction of real and credible simulated work situations and the use of $s$ tudents' workplace experience and establishment of related learning activities. In the United States, it is generally believed that teaching contents and teaching means and methods shoul $\mathrm{d}$ be contextualized. Contextualization focuses on task and problem-based teaching. The prob lems must have a certain value, which are closely related with student's family needs, com munity needs, internship and probation. They fully reflects the modern student-centered educ ation and teaching idea, realizing the goal of cultivating students' comprehensive vocational abilities. 
Therefore, the curriculum implementation based on occupation contextualization is a formi ng process of work meaning and occupational values and the development process of stude nt's occupational reason, emotion and individual personality and so on. The relationship bet ween knowledge and tasks must be clarified in students' occupational quality education, whi ch should be integrated into the specific occupational context in order to achieve the educat ional effect.

\section{Ccurriculum evaluation focuses on results and generation}

In the field of occupational quality, curriculum objectives are student-based development concepts. Curriculum evaluation centers on not only students' mastery of knowledge and skil ls training,but students' comprehensive and sustainable development. The purpose of curricul um evaluation is to promote the individual life wisdom and personality development, career development, and the fullness of the life spirit. It takes the evaluation of the past of objec ts as a starting point, focusing on the evaluation of the reality of objects and the future of objects. So it is necessary to change the past curriculum evaluation. The evaluation index emphasizes both knowledge and skills, and reflects the quality and ability, and integrates th e feelings, beliefs, attitudes, behavior etc. It is necessary to point out that curriculum evalua tion should focus on the individual characteristics and differences of evaluation objects. Iden tify personalized development direction with the evaluation objects to fully develop their init iative of self-evaluation, making their life value reflected in the development process.

\section{Conclusions}

Thus, the genuine curriculum education should contain both explicit knowledge and meth od teaching and implicit occupational qualty developing. Dewey said: "if any education is $\mathrm{j}$ ust to impart skills, then this kind of education is not free and immoral; moreover, utilitari an teaching is at the expense of the development of imagination, aesthetic ability, and the e nhancement of sense and knowledge...... not only detrimental to the free education, but als o limits the use of knowledge." [6]Consequently, In the field of vocational education, occup ational skills are the basic contents of vocational education, We need to create an environm ent for higher vocational students' comprehensive development, giving them guidance and co mmitted to improving their occupational qualty, which is the historical mission of vocational education.

\section{Acknowledgments}

Corresponding author: Wei Qin, Emergency Department, Xiangyang Central Hospital, affi liated Hospital, Hubei University of Arts and Sciences, email: 1444672356

\section{References}

[1]Zhu xiaobin, cultural morphology and professional education, the cultural analysis of educati on mode in Germany [J]. Comparative study,1996(6):21.

[2][6]Zhao xianglin, wang chengxu, duwei education. [M]. Shanghai: east China normal univer sity press,1981: 213.216.

[3]Ma ji yong. University thought politics education new theory [M]. Changchun: jilin educatio n publishing house,1992:236.

[4]Chen lisi. Thoughts and politics of the contemporary world. [M]. China renmin university p ress,1999:102.

[5]Xu guoqing, professional education curriculum theory [M]. Shanghai: east China normal uni versity press,2010:80. 